\title{
El Desarrollo de la Desaparición Forzada y sus Elementos Especiales de Configuración en Colombia
}

\author{
The development of forced disappearance and its special elements of \\ configuration in Colombia
}

Professor and investigator of the Faculty of Law from the Universidad Militar Nueva Granada, Bogotá. Specialist in Public Law from the Universidad Nacional de Colombia. Postgraduate studies in Constitutional Law from the Universidad de Salamanca, Spain.E-mail: jaime.sandoval@unimilitar.edu.co, jaisandoval@yahoo.com.

Fecha de recepción: 20 de septiembre de 2011 Fecha de evaluación: 27 de septiembre de 2011 Fecha de aprobación: 14 de noviembre de 2011

RESUMEN. El delito de desaparición forzada constituye uno de los crímenes más graves contra la comunidad internacional, tanto así que es considerado un crimen de lesa humanidad conforme al Estatuto de Roma de 1998, para el establecimiento de la Corte Penal Internacional. No obstante la importancia del 
delito en mención, tan sólo desde el año 2000 se observa su tipificación en Colombia, pese a que se reportan antecedentes de la conducta analizada, desde finales de los años 70. Pese a lo anterior, los avances en el derecho interno son significativos y constituyen la perspectiva actual de persecución de crímenes internacionales en Colombia, con las consecuencias que frente a la comunidad internacional ello representa.

PALABRAS CLAVES. Desaparición forzada, Crimen Internacional, Crimen de Lesa Humanidad, Desarrollo legislativo, persecución internacional.

ABSTRACT. The crime of enforced disappearance is one of the most serious crimes against the international community, so much so it is considered a crime against humanity under the Rome Statute of 1998 , for the establishment of the International Criminal Court. However the importance of the offence in question, only since the year 2000 notes his characterization in Colombia, despite the fact that reported a history of the analysed conduct, since the end of the 1970s. However, advances in the domestic law are significant and are the current prospect of prosecution of international crimes in Colombia, with the consequences that this represents to the international community. 
KEY WORDS: Disappearance enforced, international crime, crime against humanity, legislative development, international prosecution.

Tipo de artículo: Avance de Investigación, Centro de Investigaciones Facultad de Derecho Universidad Militar Nueva Granada.

\section{Introducción}

En un Estado de Derecho, el control mismo, ha de estar sometido a una regulación jurídica, no puede ser arbitrario ni ejercido a voluntad del jefe de Estado o del Gobierno, sino que está sometido a determinados límites y formas impuestos por la regulación jurídica (BUSTOS R. Juan, 1986 P. 173). Es precisamente en ese ámbito de regulación que la libertad como fundamento de ejercicio de los derechos fundamentales, tanto inherentes al ser humano, como derivados de tal condición, permiten inferir que aquellos actos no legitimados que restrinjan dicho ámbito, hasta el punto de desaparecer su núcleo esencial, impidan desarrollar un contexto democrático del Estado. 
Puede denominarse Estado pero muy probablemente no es un Estado de derecho y menos aún, un Estado social y democrático de derecho. Frente a este fenómeno derivado del ejercicio ilegítimo del poder, de las tensiones entre las políticas de la seguridad nacional, la preservación del orden público, el ejercicio del orden jurídico etc., bien sea por parte del Estado o por la presión y actuaciones de los grupos armados ilegales como ocurre en Colombia, surgen los mecanismos internos de protección de los derechos fundamentales, no sólo en el ámbito interno, sino también en la comunidad de naciones.

Es precisamente en este contexto en donde se desarrollan los cuestionamientos a conductas como la desaparición forzada que más allá de aparecer descritas en un código penal y de causar consecuencias dogmáticas propias, se trata de un fenómeno que reside en la pura esencia del sistema democrático, con sus efectos tanto en la credibilidad del Estado, en las prerrogativas que el mismo brinda para disentir; para oponerse al mismo; para elegir y ser elegido etc. Si esta libertad es reprimida, por la fuerza bajo las implicaciones de la desaparición forzada, esa sociedad carecerá de sentido y de futuro. Sus heridas tardarán en sanar y muchas generaciones tendrán que asumir los costos de su ejercicio como en Argentina y Chile, por sólo citar dos casos.

No obstante, el alcance de la aseveración anterior, en el presente actual, el tema no ofrece duda frente a su represión, toda vez que las inquietudes, se originan 
más que todo, en la configuración universal y amplia que ha sido concebida en el derecho colombiano y si los elementos concebidos pueden ser interpretados en el sistema penal vigente dada la totalidad y amplitud reseñada. En efecto, de un lado, se reclama que este delito sólo tiene sentido en la medida en que su comisión tenga como sujetos activos a agentes estatales y de otro lado, aparecen aquellos que apoyan la postura asumida en el Código penal, pues se trata de una conducta creada en el contexto nacional, en donde los primeros y los particulares también pueden realizar la conducta motu proprio. Frente a esta última postura, surge la duda de si en este caso, en primer lugar, es posible tal categoría frente al delito analizado y en últimas, si se tiene en forma inevitable, la necesidad de acudir en tal caso, a la conexión tradicional derivada de los derechos humanos, relativa al apoyo anuencia o aquiescencia de agentes estatales, para su efectiva producción. Por este motivo se analizarán las dificultades en su interpretación, sobre todo cuando se trata de la comisión de conductas por parte de particulares, objeto que se pretende revisar en el presente trabajo mediante un trabajo hermenéutico y analítico que toma herramientas históricas, descriptivas, comparativas y en la medida de lo posible propositivas. 


\section{El alcance internacional de la conducta de desaparición forzada}

Colombia dentro de sus compromisos internacionales adquiridos en virtud de la Corte Interamericana de Derechos Humanos ha sido objeto de juzgamiento en diferentes asuntos relacionados con la desaparición forzada como el caso Caballero Delgado y Santana por hechos ocurridos en 1989, en el cual fueron desestimadas las excepciones preliminares presentadas por Colombia en 1994. El Estado en tal virtud fue condenado mediante Sentencia de la Corte Interamericana de Derechos Humanos de 29 de enero de 1997 (Corte Interamericana de Derechos Humanos Sentencia de 29 de enero de 1997 Disponible en: http://www.corteidh.or.cr/docs/casos/articulos/seriec_31_esp.pdf.

Consultada el 10.06.2011).

Así mismo, la Organización de los Estados Americanos (OEA), en virtud del depósito de instrumentos de 12 de abril de 2005, manifestó que Colombia se une a otros 10 países que han ratificado la Convención, oficialmente conocida como la "Convención Interamericana sobre la Desaparición Forzada de Personas". La Convención entró en vigor en 1996. Los otros países que han ratificado la Convención son Argentina, Bolivia, Costa Rica, Guatemala, México, Panamá, Paraguay, Perú, Uruguay y Venezuela (Programas de Información Internacional, 
Depto de Estado-USA, 2004. Disponible en http://www.USINFO.STATE.GOV, consultada el 2.08.2011) ${ }^{1}$.

Por otra parte, resulta de particular interés señalar, que el legislador nacional, al contemplar el delito de desaparición forzada, toma elementos consagrados en los artículos correspondientes a la Convención, con la diferencia de que en la misma, se establece la prevalencia de la responsabilidad de servidores del estado por tales hechos. Sin embargo, como se verá más adelante ello obedece al particular contexto que ofrece el país en este sentido.

\title{
"...CONVENCIÓN INTERAMERICANA SOBRE DESAPARICIÓN FORZADA DE PERSONAS.
} Adoptada en Belém do Pará, Brasil el 9 de junio de 1994, en el vigésimo cuarto período ordinario de sesiones de la Asamblea General

\begin{abstract}
ARTICULO II
Para los efectos de la presente Convención, se considera desaparición forzada la privación de la libertad a una o más personas, cualquiera que fuere su forma, cometida por agentes del Estado o por personas o grupos de personas que actúen con la autorización, el apoyo o la aquiescencia del Estado, seguida de la falta de información o de la negativa a reconocer dicha privación de libertad o de informar sobre el paradero de la persona, con lo cual se impide el ejercicio de los recursos legales y de las garantías procesales pertinentes.
\end{abstract}

\footnotetext{
${ }^{1} \mathrm{Al}$ felicitar a Colombia por la ratificación de la Convención, el secretario general en funciones de la OEA, Luigi Einaudi, dijo que este país andino "se compromete a informar, tan pronto como sea posible, sobre el paradero de las personas que se presume han sido forzadas a desaparecer.
} 


\begin{abstract}
ARTICULO III
Los Estados Partes se comprometen a adoptar, con arreglo a sus procedimientos constitucionales, las medidas legislativas que fueren necesarias para tipificar como delito la desaparición forzada de personas, y a imponerle una pena apropiada que tenga en cuenta su extrema gravedad. Dicho delito será considerado como continuado o permanente mientras no se establezca el destino o paradero de la víctima.
\end{abstract}

Los Estados Partes podrán establecer circunstancias atenuantes para los que hubieren participado en actos que constituyan una desaparición forzada cuando contribuyan a la aparición con vida de la víctima o suministren informaciones que permitan esclarecer la desaparición forzada de una persona..." Disponible en http://www.oas.org/juridico/spanish/firmas/a-60.html Consultada el 10.06.2011

Frente a lo anterior, también es de particular importancia observar que el legislador se anticipó a la entrada en vigencia del Instrumento, con lo cual, su desarrollo en el derecho interno fue primero que la ratificación.

De igual forma, dentro de las medidas adoptadas en contra de la desaparición forzada en Colombia, es de observar que el instrumento citado, hace parte de las normas del bloque de constitucionalidad consagradas en el art. 93 de la Constitución Política y por lo tanto tiene prevalencia en el derecho interno. En segundo lugar, uno de los compromisos más importantes en la convención, a los cuales el Estado no puede sustraer su cumplimiento, lo constituye el hecho de que 
no es posible invocar como delito político a la desaparición forzada para efectos de extradición, de acuerdo con los siguientes términos:

\section{“...CONVENCIÓN INTERAMERICANA SOBRE DESAPARICIÓN FORZADA DE PERSONAS.}

ARTICULO V: La desaparición forzada de personas no será considerada delito político para los efectos de extradición. La desaparición forzada se considerará incluida entre los delitos que dan lugar a extradición en todo tratado de extradición celebrado entre Estados Partes. Los Estados Partes se comprometen a incluir el delito de desaparición forzada como susceptible de extradición en todo tratado de extradición que celebren entre sí en el futuro. Todo Estado Parte que subordine la extradición a la existencia de un tratado y reciba de otro Estado Parte con el que no tiene tratado una solicitud de extradición podrá considerar la presente Convención como la base jurídica necesaria para la extradición referente al delito de desaparición forzada. Los Estados Partes que no subordinen la extradición a la existencia de un tratado reconocerán dicho delito como susceptible de extradición, con sujeción a las condiciones exigidas por el derecho del Estado requerido. La extradición estará sujeta a las disposiciones previstas en la constitución y demás leyes del Estado requerido..." Disponible en http://www.oas.org/juridico/spanish/firmas/a-60.html Consultada el 10.06.2011

De otra parte y como se puede observar, son muchos los aspectos relevantes para la comunidad internacional, los que concurren en el ámbito de la desaparición forzada y muchos los que interesan al Estado colombiano, particularmente aquellos que deben estar destinados a impedir su producción, bien desde su 
prevención o todo lo que le corresponde a las consecuencias derivadas del conflicto interno que la generan.

Así mismo, como se verá, esta conducta es mucho más que un concepto dogmático jurídico penal, es un atentado de lesa humanidad que Interesa a la comunidad internacional, al sistema democrático y a la sociedad, tanto así que incluso, las naciones unidas en el Estatuto de Roma, literal (i) artículo $7^{0}$ (Desaparición forzada de Personas) lo describe dentro de las conductas susceptibles de la competencia de la Corte Penal Internacional.

Sobre este aspecto, llama la atención nuevamente que el legislador colombiano, toma ciertos ingredientes que se desarrollan en el artículo 165 del Código Penal, del delito de desaparición forzada en los términos que están expresados en el literal (i) numeral $2^{\circ}$ del artículo $7^{\circ}$ del Estatuto de Roma, en los siguientes términos:

“...Artículo $7^{\circ}$ (Estatuto de Roma)

\section{Crímenes de lesa humanidad}

2. A los efectos del párrafo 1 :

i) Por "desaparición forzada de personas" se entenderá la aprehensión, la detención o el secuestro de personas por un Estado o una organización política, o con su autorización, apoyo o aquiescencia, seguido de la negativa a admitir tal privación de libertad o dar 
información sobre la suerte o el paradero de esas personas, con la intención de dejarlas fuera del amparo de la ley por un período prolongado..."

En todo caso, en Colombia no se han desarrollado en la ley penal, los elementos de sistematicidad y generalidad necesarios para la configuración de las conductas de lesa humanidad exigidas en el Estatuto de Roma citado. Salvo los avances que aparecen en decisiones relativas a la ratificación del instrumento citado y la declaratoria de excequibilidad tanto del tratado como de los elementos del crimen, no aparecen desarrollos internos tendientes a configurar y castigar este delito como crimen internacional ${ }^{2}$. Pues en todo caso, tal y como sigue configurado en el derecho interno, la conducta de desaparición forzada, continua bajo un esquema de delito ordinario con elementos que interesan al análisis dogmático en concreto y que presenta diferencias frente a la tradición internacional en este sentido, lo cual, en todo caso, obedece a las circunstancias de nuestro contexto de conflicto y violencia de más de 60 años de existencia, tal y como se desarrolla a continuación.

\footnotetext{
${ }^{2}$ El estatuto de Roma fue declarado exequible por la Corte Constitucional Colombiana mediante sentencia C578 de 30 de julio de 2002, Magistrado Ponente Dr. Manuel José Cepeda Espinosa.
} 


\section{La desaparición forzada en Colombia. Contexto histórico}

El grave fenómeno de la desaparición forzada en Colombia no es ajeno a nuestro país, tanto así que en el informe de Amnistía Internacional de 1998, sobre desapariciones forzadas y homicidios políticos se relata:

\footnotetext{
"En 1,978 se tuvo constancia por primera vez de la existencia en Colombia de los sombríos "escuadrones de la muerte", que amenazaron a los abogados de los presos políticos y a los miembros de la Corte Suprema de Justicia que emitieron opiniones contrarias al Estatuto de Seguridad Antiterrorista, promulgado ese mismo año. A partir de 1.980, a medida que empezaba a disminuir el número de detenidos políticos, Amnistía Internacional fue recibiendo cada vez más informes de tortura y homicidio de campesinos en las zonas de conflicto; esas torturas y homicidios las cometían las fuerzas de contrainsurgencia del Ejército colombiano y los grupos paramilitares que colaboraban con ellos. Al mismo tiempo aumentó significativamente el número de "desapariciones".
}

En efecto, el uso de la desaparición forzada para eludir la responsabilidad del Estado fue descrito por el ex-procurador general de Colombia Carlos Arrieta Padilla de la siguiente manera: "Sus autores trazan con premeditación el iter criminis, no dejando rastro, huella o evidencia alguna que permitan establecer las circunstancias que rodearon el hecho; se ampara calculadamente la impunidad y se aprovecha el temor de los familiares y testigos que les impide denunciar directamente la desaparición, prefiriendo hacerlo a través de terceros; todo lo cual 
conduce a que la investigación sea ciertamente difícil frente a este tipo de violación de derechos humanos".

En 1.985 se constituyó formalmente la Asociación de Familiares de Detenidos Desaparecidos de Colombia (ASFADDES), que venía trabajando desde 1.982. El primer hecho que la motivó a actuar fue la desaparición de 14 estudiantes de la Universidad Distrital en 1.982. En 1.998 se registraron 39 casos de desaparición forzada. Según ASFADDES de 1.995 a 1.997 fueron registrados 74 casos. Fuentes no oficiales señalaron la desaparición forzada con episodios no declarados por el Estado, a partir del 10 de septiembre de 1.977, con la desaparición de militantes de izquierda (Revista Voz, 1998. Disponible en http: / /www.nodo50.org/voz, consultada el 2.08.2011).

Por otra parte, según el informe anual de la defensoría del pueblo, la desaparición forzada es un factor que acentúa la degradación del conflicto armado colombiano. Un informe elaborado por la comisión de derechos humanos de la ONU, publicado en marzo de 1997 señaló para ese entonces la existencia de 756 desaparecidos (4 Informe anual Defensoría del Pueblo, 1997, P. 47).

La desaparición forzada ocupa a la comunidad internacional, frente al problema colombiano a tal punto, que el Departamento de Estado de Estados Unidos 
observó en sus "Informes por Países sobre Prácticas de Derechos Humanos" de 2004 que las desapariciones forzadas, muchas de ellas políticamente motivadas, continúan azotando a Colombia y que los grupos paramilitares de derecha son responsables de la mayoría de esas desapariciones. (Programas de Información Internacional, Depto de Estado-USA, 2004. Disponible en http://www.USINFO.STATE.GOV, consultada el 2.08.2011)

Según el Departamento de Estado ocurrieron 65 casos de desapariciones forzadas en Colombia durante los primeros seis meses de 2004 y se acusó a las fuerzas de seguridad de Colombia de la responsabilidad directa en 17 de dichos casos. Por otra parte el Grupo de Trabajo de las Naciones Unidas sobre la Desaparición Forzada o Involuntaria informó en 2003 que por lo menos 1.114 casos de desapariciones forzadas tuvieron lugar en Colombia desde 1981, de los cuales, según el Departamento de Estado, 850 siguen sin esclarecerse. El Grupo de Trabajo agregó que mientras que en el pasado las desapariciones estaban asociadas principalmente con las políticas gubernamentales de regímenes autoritarios, "hoy en día ocurren dentro del contexto de situaciones mucho más complejas de conflictos internos que generan violencia, crisis humanitarias y violaciones de los derechos humanos" (Programas de Información Internacional, Depto de Estado-USA, 2004. Disponible en http://www.USINFO.STATE.GOV, consultada el 2.08.2011). 
Por otra parte, el comité internacional de la Cruz Roja en Colombia, registra que en el año pasado recibió 279 nuevos casos, "que se suman a más de 2.000 desapariciones documentadas desde 1994 en relación con el conflicto armado". Esta cifra, advierte este organismo, incluye únicamente los casos conocidos por la institución "y no pretende ser exhaustiva", aunque evidentemente muestra una tendencia.

El Comité considera que la desaparición persiste "como método de intimidación contra la población civil en Colombia". Y dice que este tema específicamente "debería ocupar un lugar privilegiado en el marco de los procesos de negociación entre el Estado y los grupos armados organizados".

Las estadísticas que se manejan en Colombia registran que así como las guerrillas son las responsables de la mayoría de los secuestros, los paramilitares recurren ordinariamente a las desapariciones forzadas. Algunas estadísticas atribuyen esta última práctica incluso a agentes estatales (EL.TIEMPO, Sección, Conflicto Armado Derechos Humanos. Mayo 6 de 2005.). 


\section{Las acciones legislativas del Estado en la desaparición forzada.}

En 1998, la defensoría del pueblo reclamaba del Estado que a pesar de que la Constitución Política en su artículo 12 señala que "Nadie será sometido a desaparición forzada" la legislación penal colombiana no contemplaba como hecho punible la conducta del servidor público que hiciera desaparecer a una persona (4 $4^{\circ}$ Informe anual, Defensoría del Pueblo, 1997, pag. 46). Como se puede ver desde este momento se mencionaba al servidor público como posible autor de la conducta analizada, sin embargo no se analiza con profundidad los bienes susceptibles de vulneración en tales crímenes.

De igual forma, por este tiempo los gobiernos de los presidentes de Colombia, Cesar Gaviria (1990 - 1994) y Ernesto Samper Pizano (1994 - 1998) objetaron parcialmente un proyecto que intentaba introducir la conducta examinada, circunstancia que impidió dar curso a la iniciativa. Una de las objeciones se refería al juzgamiento de los desaparecedores pertenecientes a la fuerza pública por jueces ordinarios, y la otra, consistía en el rechazo de la invocación de la obediencia debida como justificante del hecho. Tras las objeciones citadas el proyecto fue archivado en 1996 (4 Informe anual, Defensoría del Pueblo, 1997, pag. 46). En el mismo sentido se observa la conexión de agentes estatales en el ilícito. 
Posteriormente, las normas sobre el crimen en cuestión, aparecen inicialmente reguladas por la ley 589 de 2000, que estableció el delito de desaparición forzada, junto con las circunstancias de agravación y atenuación punitiva. Estas conductas fueron adicionadas al Código Penal vigente para ese entonces (Decreto Ley 100 de 1980) en los artículos 268 A, 268 B y 268 C, para que finalmente, la desaparición forzada fuera definida en el primer artículo, bajo los condicionamientos que presenta la norma actual en el art. 165 ley 599 de 2000, salvo las modificaciones realizadas por la declaratoria de parcial de inexcequibilidad de la Corte Constitucional en los siguientes términos:

“...Art. 165 Desaparición Forzada. El particular que perteneciendo a un grupo armado al margen de la ley someta a otra persona a privación de su libertad cualquiera que sea la forma, seguida de su ocultamiento y de la negativa a reconocer dicha privación o de dar información sobre su paradero sustrayéndola del amparo de la ley, incurrirá en prisión de veinte (20) a treinta (30) años, multa de mil (1000) a tres mil (3000) salarios mínimos legales mensuales vigentes y en interdicción de derechos y funciones públicas de (10) a veinte (20) años.

A la misma pena quedará sometido, el servidor público, o el particular que actúe bajo la determinación o la aquiescencia de aquél, y realice la conducta descrita en el inciso anterior..."(La parte en negrilla subrayada fue declarada inexequible. CORTE CONSTITUCIONAL. Sentencia C.317 DE 2002) 
Así mismo, en el inciso 4ํㅜ del artículo 166 (Ley 599 de 2000) relativo a las circunstancias de agravación punitiva, se estableció un aspecto de suma importancia relativo a la naturaleza de la desaparición forzada, cuando la conducta se cometa, por razón de sus calidades, contra las siguientes personas: Servidores públicos, comunicadores, defensores de derechos humanos, candidatos 0 aspirantes a cargos de elección popular, dirigentes sindicales, políticos o religiosos, contra quienes hayan sido testigos de conductas punibles 0 disciplinarias, juez de paz, o contra cualquier persona por sus creencias $u$ opiniones políticas o por motivo que implique alguna forma de discriminación o intolerancia.

Como se puede ver desde el comienzo de su tipificación inicial, se mencionó la posibilidad de particulares como posibles autores de la conducta e incluso el tipo fue más allá y calificó en este momento, a miembros de grupos armados ilegales como participes del delito en cuestión.

Sin embargo, la sentencia C-317 de 2 de mayo de 2002, señaló la declaratoria de inconstitucionalidad en este sentido, puesto que la misma obedecía a la reducción del ámbito de protección del art. 12 de la Carta Política, en razón de que los miembros de la fuerza pública u otros funcionarios públicos, pueden ser sujetos activos de la conducta, en forma directa o indirecta, conforme al inciso $2^{\circ}$ del artículo 165 del C.P. (López Díaz C., 2009 pp. 80 y 81) 
Así mismo, según López Díaz C. (2009 pp. 80 y 81) la Corte Constitucional declara inconstitucional la expresión demandada, debido a que podrían ser excluidos de la conducta particulares que no pertenecen a ningún grupo, es decir, a quien realiza la conducta punible individualmente, motu proprio; al particular que pertenezca a un grupo no armado y al particular que pertenezca a un grupo que no esté al margen de la ley (Sentencia C-317 de 2002).

De igual forma, la sentencia concluye que ello obedece a la realidad nacional, y que ello refleja diversos grupos que pueden ser objeto de la conducta y no necesariamente servidores públicos, como se desarrolla en el contexto internacional. Esta una consideración resulta muy local del problema que involucra supuestos particulares, deducibles del contexto del conflicto colombiano, a diferencia de lo que podría suceder en legislaciones internacionales. No obstante, persiste la duda al respecto, puesto que se plantea el interrogante de como se exige el deber a un particular, que no tiene la obligación de amparar bajo las garantías de la ley a las personas. Incluso la sentencia asevera que la conducta en este caso se produce en el caso de los autores particulares, en las modalidades de negativa a reconocer la privación de la libertad de la persona o de dar información sobre su paradero, aspectos que no profundizan en la circunstancia de sustraer a la persona precisamente del amparo de la ley. 
De todas maneras, la conducta posterior a la declaratoria de inexequibilidad de esta mención, dejó aun más abierta la posibilidad de autoría de particulares, sin resolver la duda anterior, al dejar una tipicidad sobre un autor indeterminado, junto con la posibilidad de comisión de los agentes estatales, como se observa en el siguiente aparte.

\section{La definición final de la desaparición forzada en la actualidad.}

En definitiva el delito de desaparición forzada en el derecho interno, fue configurado en los siguientes términos:

“...Art. 165.-Desaparición Forzada-El particular que someta a otra persona a privación de su libertad cualquiera que sea la forma, seguida de su ocultamiento y de la negativa a reconocer dicha privación o de dar información sobre su paradero, sustrayéndola del amparo de la ley, incurrirá en prisión de veinte (20) a treinta (30) años, multa de mil (1000) a tres mil (3000) salarios mínimos legales mensuales vigentes y en interdicción de derechos y funciones públicas de diez (10) a veinte (20)años.

A la misma pena quedará sometido, el servidor público, o el particular que actúe bajo la determinación o la aquiescencia de aquél, y realice la conducta descrita en el inciso anterior..."

Revista Virtual Via Inveniendi Et Iudicandi. Edición 13, Vol. 7, No 1, enero - junio de 2012 
Sobre el alcance del delito analizado, el Profesor Alejandro Aponte señala que en el artículo 165 del C.P., se desarrolla una redacción problemática, pues no se entiende muy bien por qué razón se divide la norma en dos incisos, cuando el segundo, que se refiere al servidor público, no contiene por ejemplo una sanción más grave. En cualquier, caso, según su opinión, se trata de una conducta que puede ser cometida por cualquiera. (APONTE CARDONA A. 2003. P. 212).

\subsection{Aspectos relevantes frente a la conducta de desaparición forzada}

En este sentido, se destaca la universalidad concebida en el tipo nacional, toda vez que no se vincula a una calificación especial del autor, para la ejecución de la conducta, sin embargo se dividen las dos modalidades de la conducta, es decir mediante un autor indeterminado y a través de agentes estatales.

El doctor Aponte añade que para diferenciarse por ejemplo, del secuestro o de otros delitos contra la libertad, se subraya en la norma “...la protección de la personalidad humana como constructo jurídico: el derecho a ser persona y ser tratado como tal en el contexto de un orden jurídico. La conducta sustrae precisamente a la persona del amparo de la ley..."(APONTE CARDONA A. 2003. P. 
212). Es decir, se priva a la persona de sus derechos y sobre todo de las garantías a conocer la razón por la cual se está privada de la libertad.

De todas maneras, subsiste la inquietud de si este reconocimiento de garantías que son vulneradas, es posible reclamarla de particulares. Tal vez, esta última exigencia se puede interpretar como lo indica la Corte Constitucional en la Decisión C-312 de 2002, en el caso de las modalidades de no reconocer la privación o no dar información sobre el paradero de la víctima. No obstante, se puede precisar que en nuestro caso la tesis puede ir dirigida, a impedir que la persona acuda a las autoridades para su auxilio o que las mismas, a pesar de conocer de la desaparición tengan algún vínculo con la participación de los particulares autores del ilícito.

Frente a este aspecto, en criterio del profesor Córdoba Triviño se advierte que la característica principal de dicha conducta, se remite a sacar a la persona de la protección legal, es decir que su ocultamiento le impide ejercer sus derechos. De esta manera, no sólo se le impide ejercer sus derechos como persona, sino también, se le priva de no conocer información con respecto a su paradero, que corresponde a la principal característica de la desaparición forzada (CORDOBA TRIVIÑO J. 2001 P. 162 y 163) 
En síntesis, la desaparición forzada desde las modalidades de la conducta, puede dividirse en dos fases, la primera relativa a la privación de la libertad y la segunda a la no información sobre dicha privación con la sustracción de los derechos derivados del amparo de la ley. Sobre este aspecto Ambos K. y Bhöm M.L. (2009 p. 210 y 211), sostienen que la primera fase se desarrolla cuando se hace desaparecer a la persona, con las consecuencias señaladas (nivel personal de afectación del bien jurídico) e impedir que la administración de justicia pueda ejercer sus deberes jurisdiccionales y de protección (nivel colectivo de afectación del bien).

En la primera fase, es necesario observar que si se trata de la conducta tradicional sujeta a la producción de la desaparición forzada por parte de agentes estatales, esta privación en principio no sería ilegal, pues las autoridades ejecutoras tendrían algún rasgo de competencia para hacerlo y la segunda fase, seguiría después de no informar a la persona, sobre los motivos de la retención y a negarle sus derechos o amparo legal. Por otra parte si se trata de la conducta nacional, la situación desde el comienzo, se constituiría en ilícita, en lo que hace referencia al primer inciso del art. 165 del C.P., pues se refiere a la conducta cometida por cualquier persona, entre ellas a los particulares. Por su parte el segundo inciso si correspondería a esta interpretación inicial. 
En cuanto a la segunda fase, la no información sobre el paradero de la persona, constituye un elemento esencial de la conducta, pues con ella se impide a la persona acudir a reclamar sus garantías para que se aclare los motivos de su retención (Ambos K. y Bhöm M.L., 2009 p. 233). Por ello se menciona que se trata de la conducta de sustraer a la persona del amparo legal. En todo caso en la norma nacional este asunto debe ser observado bien como la conducta omitiva de agentes estatales o bien la conducta de particulares que impiden que la persona desaparecida, acuda a los mecanismos legales correspondientes para reclamar su libertad, es posible que desde este punto de vista se resuelva la duda de la desaparición realizada por particulares que desde el punto de vista internacional se considera excesiva en la tipicidad colombiana Ambos K. y Bhöm M.L. (2009 p. 218).

\subsection{El bien jurídico, características y otros aspectos de la conducta de desaparición forzada}

El bien jurídico de la desaparición forzada tanto en el ámbito internacional (Art. $7^{\circ}$ Lit.i.- Estatuto de Roma de 1998), como en el delito nacional (Arts. 165 y ss del C.P. colombiano), coinciden en que el bien jurídico afectado con la desaparición

forzada es múltiple (Ambos K. y Bhöm M.L., 2009 p. 245), pues en primer lugar tiene un nivel de vulneración individual, toda vez que se afecta la libertad individual 
con la privación de la libertad de la persona, como su integridad e incluso su vida(Lesiones personales, tortura, homicidio de la persona desaparecida). A su vez se afecta un nivel frente a la seguridad en general e incluso la seguridad jurídica y el factor familiar pues las victimas afectivas del hecho, corresponden precisamente a los familiares que no pueden reclamar la desaparición. En tercer lugar se afectan bienes jurídicos colectivos, toda vez que la sociedad se observa debilitada en su aparato de administración de justicia, por la imposibilidad de ejercer los recursos para el reclamo del paradero de la persona, sus derechos garantías etc. Y sobre todo de la verdad histórico-social sobre el hecho (Ambos K. y Bhöm M.L., 2009 p. 245).

Ahora bien, frente a la característica de permanencia de la conducta, es preciso determinar que este elemento se consuma en el momento en que se incumple el deber de informar sobre el paradero de la persona y continua en su ejecución mientras este deber no sea satisfecho (Ambos K. y Bhöm M.L. 2009 p. 249). Es decir mientras el perpetrador no informe sobre el paradero de la persona este hecho continua vigente, actividad que es predicable en el caso nacional tanto a particulares como para agentes estatales vinculados en la acción.

De igual forma al analizar el contenido del artículo 166 del C.P., se señala que la norma consagra diversas y complejas circunstancias de agravación de la desaparición forzada, pues el delito en cuestión se agrava, "cuando la conducta se 
cometa por quien ejerza autoridad o jurisdicción". (APONTE CARDONA A. 2003. P. 213).

Es decir, si bien el inciso segundo del artículo 165 se refiere al servidor público de manera genérica, la conducta se agrava en el caso específico de ciertos funcionarios con calidades especiales. Reitera que todo esto puede generar mucha confusión porque se trata de "escalas", por decirlo así, de personas que pueden ser sujetos activos de la conducta (APONTE CARDONA A. 2003. P. 213).

En todo caso, la norma subraya la intención general del Código en función de la protección de la diferencia que se concreta en las agravantes: Por ejemplo si la conducta se comete contra cualquier persona, "por sus creencias u opiniones políticas o por motivo que implique alguna forma de discriminación o intolerancia". Así mismo en el numeral $6^{\circ}$ se agrava la conducta cuando esta se "cometa utilizando bienes del Estado". Por su parte, el numeral $7^{\circ}$ lo hace cuando "se somete a la víctima a tratos crueles, inhumanos o degradantes durante el tiempo en que permanezca desaparecida, siempre y cuando la conducta no configure otro delito" (APONTE CARDONA A. 2003. P. 213).

De la misma forma que en el caso del homicidio, en los delitos que están situados en el ámbito de la protección de la libertad, como la desaparición, es 
necesario de acuerdo con lo sostenido por el profesor Alejandro Aponte (2003 P. 213) ser cautos en su interpretación, en el contexto de la persecución nacional de los mismos. Tales casos según esta postura se refieren al secuestro y, a partir de normas especialmente complejas como las situadas en el capítulo $4^{\circ}$ de este mismo título, como la detención arbitraria. En este caso, el doctor Aponte recomienda, que es necesario hacer lecturas sistemáticas de las normas, aplicar el principio de integración y actuar en consonancia con criterios señalados en los instrumentos internacionales (APONTE CARDONA A. 2003. P. 214).

Lo anterior, tiene sentido toda vez que tal y como lo sostiene Córdoba Triviño (2001. Pp. 165 y 166), la desaparición forzada, debido a los actos que rodean su ejecución, puede concursar con otras conductas como la tortura o el homicidio y por lo tanto, en tales actuaciones se lesionan no solamente el derecho a la libertad, sino también el derecho a la vida, la integridad personal entre otros fundamentos (CORTE CONSTITUCIONAL. Sentencia C-317, 2002).

En general, la norma nacional permite tutelar, no sólo la orientación interamericana y universal que se remite a la comisión de tal conducta cuando se realice por agentes estatales o por particulares con la aquiescencia de las autoridades públicas, con lo cual es importante destacar 
su alcance internacional y sus efectos frente a la comunidad internacional. Todo ello, pese a que en algunos casos se considere desde la doctrina internacional, excesiva la tipicidad nacional. Sin embargo como se mencionó lo anterior obedece a las circunstancias del contexto nacional en donde es posible que las actuaciones efectivamente sean ejercidas por particulares atendiendo las motivaciones que puedan ser ejercidas por los grupos armados ilegales que participan en el mismo, además de la ya concebida responsabilidad que le corresponde a los agentes estatales en forma indudable en el presente caso.

\section{Conclusiones}

El delito de desaparición forzada de personas en Colombia es de reciente desarrollo y sus diferentes variables actuales han sido el resultado de un intenso debate legislativo que ha sido confrontado con la realidad de conflicto y violencia en Colombia. Tanto así que desde 1978 se reporta la aparición del fenómeno y sólo hasta el año 2000 se puede verificar plenamente su vigencia en el derecho penal colombiano. 
No obstante lo anterior, el alcance internacional, en todo caso ha intervenido en el sistema interno para derivar de allì obligaciones internacionales para el Estado Colombiano, en su responsabilidad por violaciones que se han presentado en este sentido en virtud de desapariciones forzadas ocurridas en el país. Sin embargo este hecho todavía reporta un nivel de afectación relevante en los índices de violaciones actuales por este motivo.

Es importante destacar la suscripción de instrumentos internacionales como la Convención Interamericana contra la desaparición forzada de 1994 y el Estatuto de Roma de 1998, tratados que previenen la conducta y adicionan múltiples herramientas para la persecución de estos crímenes de alcance internacional.

Pese a los avances en el derecho interno con normas como la ley 589 de 2000, que dispuso la tipificación de la conducta analizada, todavía no aparece un desarrollo interno que permita verificar tal conducta como un crimen de lesa humanidad, con todos los efectos internacionales que constituye un crimen de tal naturaleza frente a la comunidad internacional.

En todo caso la conducta nacional presenta diferencias ostensibles con el delito tipificado a nivel internacional, la responsabilidad por la desaparición forzada puede involucrar tanto a agentes estatales o particulares motu proprio o con el apoyo aquiescencia o colaboración de agentes estatales. En estos casos, las 
modalidades de la conducta se deben establecer a partir de la privación de la libertad de la persona, de la no información o negativa a suministrar su paradero y de sustraer o impedir que la persona ejerza sus garantías para reclamar los motivos de su privación o acuda ante las autoridades en su auxilio para tales efectos.

\section{BIBLIOGRAFIA}

AMBOS KAI -Coordinador- (2009). Desaparición Forzada de Personas. Análisis comparado e Internacional. Editorial Temis- Agencia Alemana para la Cooperación y el Desarrollo GIZ. Bogotá D.C.

APONTE CARDONA ALEJANDRO. Persecución penal nacional de crímenes Internacionales en América Latina y España. Ed. Fundación Konrad Adenauer Stiftung, Instituto Max Planck. Montevideo Uruguay. 2003.

BUSTOS RAMIREZ Juan, Las funciones de la Policía y la Libertad y Seguridad de los Ciudadanos. Revista Nuevo Foro Penal № 32 . Medellín, Colombia 1986.

CORTE CONSTITUCIONAL COLOMBIANA. Sentencia C-578 de 30 de julio de 2002, Magistrado Ponente Dr. Manuel José Cepeda Espinosa. 
CORTE CONSTITUCIONAL COLOMBIANA. Sentencia C-317 de 2 de mayo de 2002. M.P. Clara Inés Vargas.

LEY 599 de 2000 Diario Oficial de la Repùblica de Colombia, No. 44.097 de 24 de julio del 2000 - Código Penal y de Procedimiento Penal Colombiano. Legis editores 2011.

LEY 589 de 2000 Diario Oficial de la República No. 44.073, de 7 de julio de 2000

Constitución Política de Colombia de 1991, Impresión Presidencia de la República, Bogotá D.C. 1993.

CASO CABALLERO DELGADO Y SANTANA Vs. SANTANA. Sentencia de la Corte Interamericana de Derechos Humanos de 29 de enero de 1997 Disponible en http://www.corteidh.or.cr/docs/casos/articulos/seriec 31 esp.pdf. Consultada el 10.06.2011

CONVENCIÓN INTERAMERICANA SOBRE DESAPARICIÓN FORZADA DE PERSONAS, Adoptada en Belém do Pará, Brasil el 9 de junio de 1994, en el vigésimo cuarto período ordinario de sesiones de la Asamblea General, organización de los Estados Americanos (OEA) 
CORDOBA TRIVIÑO JAIME, (2001) Derecho Penal Internacional, Estudio de los delitos de Genocidio y de los Crímenes de Guerra con referencia al Nuevo Código Penal Colombiano, Ediciones Jurídicas Gustavo Ibáñez, Bogotá D.C. 2001.

CUARTO Informe Anual del Defensor del Pueblo - Serie documentos № 11 Defensoría del Pueblo. Bogotá 1997.

EL TIEMPO, Sección, Conflicto Armado Derechos Humanos. Panorama de secuestro y desaparición forzada en Colombia es desolador y dramático, dice la Cruz Roja, Mayo 6 de 2005.

ESTATUTO DE ROMA DE LA CORTE PENAL INTERNACIONAL, Organización de las Naciones Unidas, Roma 17 de julio de 1998. Ley 742 de 5 de junio de 2002. Publicada en el Diario Oficial de la República de Colombia No. 44.826, de 7 de junio de 2002

Programas de Información Internacional, Departamento de Estado de los Estados Unidos de América. http://www.USINFO.STATE.GOV 


\section{QUINTO INFORME ANUAL DEL DEFENSOR DEL PUEBLO AL CONGRESO DE COLOMBIA - Derechos Humanos para Vivir en Paz. ED. Defensoría del Pueblo. Imprenta Nacional. Bogotá 1998.}

Revista Voz. Edición 1995, licencia No. 002357 del Ministerio de Gobierno. Quincena del 11 al 24 de Noviembre de 1998. http://www.nodo50.org/voz 